\title{
Paranoia House
}

\author{
Arthur Kay
}

Stepped-up media reporting of violence and natural disasters have created a national ethos of paranoia and culture of fear.

S Low

News reporting capitalises on our greatest fears...focusing on symbolic substitutes rather than facing our moral insecurities and more systematic social problems.

B Glassner

A vision of the London house in 2062. The only thing we have to fear is fear itself...

Terrence Fyed is a normal man living in the area of Nine Elms, South London. He has always kept up with world news and approaches associated problems pragmatically. A psychologist in 2012 would tell Terry that he suffers from crippling paranoia. However, in 2062 he is in good company, regarded by friends and family as remarkably blasé about world crises. The stories and images that have dominated world news for the last fifty years rule his life. Over time he has made a series of architectural interventions to his detached Victorian house, attempting to address specific fears derived from perceived local and global threats. The relocation of the Unite States embassy to the area, his house's proximity to the River Thames and the recently finished nuclear reactor at Battersea PowerStation don't help Terry stay calm!

Terrence's daily routine is dominated by the news. Whilst he does still go out to work and return home every day, the amount of panic he experiences is directly proportional to the amount of news he hears. Fear spreads virally throughout the 'global community', following the usual roots of apple-facebook global.

\section{Terrence's Architectural Retrofit}

The key features or Terrence's retrofit are:

- In case of emergency flooding - space for underground water reserves.

- In case of emergency famine - live fish kept in the basements water reserves, tinned goods (10,000 stored in emergency escape route).

How to cite this book chapter:

Kay, A. 2013. Paranoia House. In: Bell, S and Paskins, J. (eds.) Imagining the Future City: London 2062. Pp.

139-140. London: Ubiquity Press. DOI: http://dx.doi.org/10.5334/bag.u 


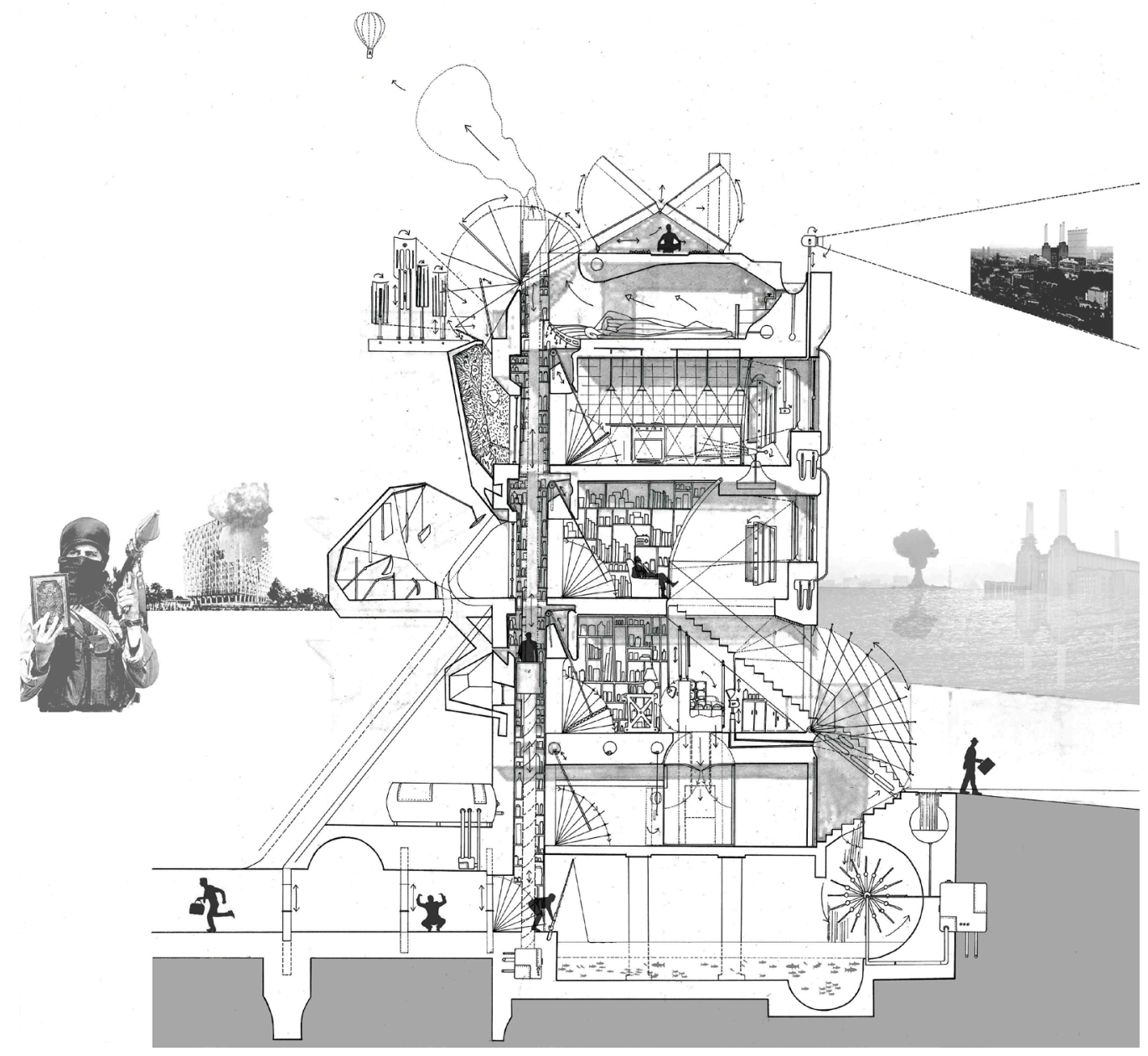

- In case of emergency unknown crisis - hydraulic lift and emergency aerial escape route via hot air balloon. This space acts as the backbone of the house providing access to the rooms and a physical escape, a vessel in which Terry can make good his escape over London away from any dangers.

- In case of emergency any-crisis - three air tight panic rooms, sealed to nuclear, chemical land ballistic terrorist attack.

- In case of emergency financial crisis - gold reserves if currency devalues.

- In case of emergency drought - water reserves in basement pool, decontamination areas for water and continual flow maintained through link to the water table.

- In case of emergency energy crisis - Terrence has ensured that hydroelectric, solar and wind energy sources are all included in his retrofit.

- In case of emergency mental distress - a series of idyllic dioramas have been assembled vertically by the hydraulic lift, providing a space for psychological release. These are in contrast to the world in which Terry lives, directly addressing some of the issues at hand.

Terrence has worked hard to retain the fabric of the building as he is anxious not to break any of the strict planning laws in the Greater London area, of which serious violation is now punishable by death. He has consequentially ensured that these alterations are not visible from the exterior of the building.

The house was our corner of the world, sheltering day-dreaming, our centre of intimacy. Now, in 2062, the idealised, proactive emotions of home have been encroached by increased globalisation, inevitable terrorist attack, environmental catastrophe, nuclear disaster, economic crises and political instability. 